\title{
Contratos de Transferência Tecnológica: Um Estudo sobre Aquisição de Tecnologia em Polímeros no Brasil
}

\author{
Carlos A. Hemais \\ Instituto de Macromoléculas Professora Eloísa Mano, UFRJ \\ Henrique M. Barros \\ Warwick Business School, University of Warwick
}

Elizabeth 0. R. Rosa

Instituto Nacional de Propriedade Industrial, RJ

\begin{abstract}
Resumo: O presente trabalho examina como as empresas brasileiras produtoras de polímeros (plásticos, borrachas e fibras) têm acesso à tecnologia para a sustentação de seus negócios. Para tanto, foi feito um levantamento junto ao INPI, objetivando conhecer os tipos de contratos de transferência de tecnologia averbados naquele instituto em um período de 17 anos. Em seguida, foram realizadas entrevistas com tecnólogos de sete empresas do setor. As entrevistas realizadas e os dados obtidos revelam que, apesar da reconhecida importância de P\&D e inovação tecnológica para a competitividade das empresas do setor, as mesmas parecem ainda ser dependentes tecnologicamente de fornecedores no exterior. Isso, entretanto, não significa que a indústria de polímeros no Brasil não realize atividades de $\mathrm{P} \& \mathrm{D}$; elas ocorrem, porém se concentram no curto prazo, visando atender às necessidades imediatas do mercado.
\end{abstract}

Palavras-chave: Transferência de tecnologia, indústria brasileira de polímeros, INPI, inovação tecnológica.

\section{Technology Transfer Contract: A Study of Polymer Technology Acquisition in Brazil}

Abstract: This paper examines how the Brazilian polymer producers (plastics, rubbers and fibers) access the technologies they need for the maintenance of their business. A study was made in INPI (Brazilian Patent Office) to ascertain what type of contract of technology transfer was registered in that office, over a period of 17 years. In addition, employees that deal with technology were interviewed in seven Brazilian polymer producers. The interviews and the data show that, in spite of the importance of that R\&D and technological innovation have for competitiveness in the polymer sector, these firms seem to be technologically dependent on foreign suppliers. This fact, however, does not mean that the Brazilian polymer industry lacks R\&D activities; there is this kind of activity but it is concentrated in the short range and is designed to attend to the immediate needs of the market.

Keywords: Technology transfer, Brazilian polymer industry, Brazilian Patent Office, technological innovation.

\section{Introdução}

A tecnologia tem-se transformado em um elemento essencial para garantir a vantagem competitiva das empresas a longo prazo. Isto se torna ainda mais verdadeiro quando se coloca essa empresa no contexto de um mundo globalizado, onde a competição por fatias de mercado é bastante acirrada. Tal tecnologia pode ser adquirida tanto de fontes externas à organização como pode ser gerada de maneira endógena. Embora a empresa nem sempre seja capaz de gerar a tecnologia de que necessita com recursos próprios e, portanto, precise recorrer a fontes externas, a constante dependência de tais fontes pode implicar numa fragilidade da sua posição competitiva. Assim, as firmas devem ter capacidade de gerar continuamente nova tecnologia para superar as imperfeições do mercado e os esforços em pesquisa e desenvolvimento (P\&D) são decisivos para manter a posição competitiva da firma.

A indústria de polímeros (plásticos, borrachas e fibras) é, talvez, o segmento da indústria petroquímica que mais cresce no Brasil. A razão desse crescimento é devida à progressiva substituição de outros materiais, tais como vidro, madeira, papel e metal, por produtos feitos a partir desses materiais sintéticos. Essa indústria é caracterizada, de acordo com Pavitt (1984), como sendo science based, por ser dependente de constantes inovações tecnológicas para que suas empresas possam se manter competitivas. Assim, a capacidade de criar tecnologia é vital para o processo de sobrevivência a longo termo no mercado.

O presente trabalho apresenta como as empresas brasileiras

Autor para correspondência: Carlos A. Hemais, Instituto de Macromoléculas Professora Eloísa Mano, UFRJ, Caixa Postal 68525, CEP:21945-970, Rio de Janeiro, RJ.E-mail: hemais@ima.ufrj.br 
de polímeros mantêm sua competitividade tecnológica, mostrando, também, as principais formas de transferência de tecnologia, em uma tentativa de avaliar o grau de dependência tecnológica na área. Isto se torna particularmente importante uma vez que o ambiente concorrencial se intensificou no Brasil em virtude da abertura de mercado e da diminuição das alíquotas de importação a partir da última década.

\section{Inovação tecnológica e competitividade}

Embora seja possível buscar competir através do atendimento ao cliente, do design, da proliferação de produtos ou do valor conferido aos mesmos (Deschamps \& Nayak, 1997), inovação pode ser a palavra-chave em ambiente em que vários atores se fazem presentes. Na indústria química, da qual polímeros faz parte, o processo de inovação está fortemente ligado à tecnologia, que tanto pode ser adquirida de fontes externas às empresas como pode ser gerada internamente (in house). Em ambos os casos as atividades de pesquisa e desenvolvimento (P\&D) se fazem necessárias; seja pela criação efetiva da tecnologia, seja pela adaptação daquela adquirida de terceiros aos propósitos ou a determinadas condições específicas.

$\mathrm{O}$ que faz os investimentos em P\&D serem diferentes dos demais é que eles geram conhecimentos que podem ser aplicados a quase toda a indústria. O conhecimento técnico é responsável por mudar a face da indústria e, consequentemente, pode alterar dramaticamente o equilíbrio de forças competitivas entre as firmas. Uma indústria tecnologicamente avançada necessita de muito esforço de $\mathrm{P} \& \mathrm{D}$ para se manter competitiva. A liderança tecnológica, que resulta de investimentos em P\&D, é um importante fator de competitividade das empresas. A transferência da tecnologia pode gerar altos lucros, possibilitar a entrada em mercados para outros produtos das empresas e permitir um acesso a outras tecnologias através do uso recíproco. As empresas investem em nova tecnologia, esperando ganhar uma vantagem de mercado a partir de sua exploração como um ativo único.

Nos últimos anos, têm aumentado consideravelmente os custos de $\mathrm{P} \& \mathrm{D}$, bem como o número de opções tecnológicas, fazendo com que muitas empresas de grande porte se associem para desenvolver inovações tecnológicas, usando sinergicamente suas forças de pesquisa e recursos disponíveis, em uma tentativa de otimizar as vultosas quantias envolvidas e minimizar o alto grau de incerteza inerente ao processo. Particularmente na indústria química, há o agravante de que ela está mais cautelosa quanto a algum tipo de risco do que há anos atrás, uma vez que os novos projetos estão cada vez mais sofisticados e envolvem gastos cada vez maiores (Thayer, 1995). Dessa forma, esses novos projetos precisam ser analisados muito criteriosamente de modo a evitar que investimentos de grande vulto sejam feitos, sem que haja qualquer possibilidade de sucesso. Nesse sentido, o tamanho da firma é uma limitação importante ao desenvolvimento de tecnologia, uma vez que há escassez de recursos financeiros e humanos. É sabido que o estado da arte de P\&D está concentrado em grandes firmas, que são as líderes no desenvolvimento tecnológico em cada mercado. Empresas multinacionais são muito eficientes em transferir tecnologia por causa de suas experiências, know-how, capacidade de mobilizar recursos financeiros e habilidades organizacionais.

$\mathrm{O}$ aspecto acima talvez possa contribuir para incentivar a busca de tecnologia em fontes externas, ao invés de incentivar o seu desenvolvimento in house. Como observado por Chesbrough \& Teece (1996), as empresas dispõem de inúmeros elementos externos para responderem e acessarem os recursos técnicos que forem necessários. Este tipo de estratégia pode ser atraente quando as empresas conseguem desenvolver internamente e guardar as competências que lhes forem essenciais para assegurar vantagens competitivas. Isto normalmente ocorre com aquelas que coordenam e controlam o avanço tecnológico em seus respectivos campos de atuação. Entretanto, os autores entendem que essa dependência de agentes externos também pode deixar a empresa vulnerável. $\mathrm{O}$ aumento dos incentivos e riscos contribuem para tornar mais difícil a coordenação entre parceiros e, sendo assim, a empresa integrada consegue resolver conflitos e coordenar as atividades para a inovação de um modo muito melhor. Sendo assim, a geração endógena talvez possa conferir mais autonomia às ações da empresa e, por conseguinte, fortalecer sua posição competitiva.

A finalidade de $P \& D$ é contribuir para a elaboração de um produto ou processo que vá ao encontro dos propósitos, desejos e necessidades dos consumidores (Bodewitz et al, 1988). Embora a existência da empresa num longo prazo dependa muito da aquisição de novos conhecimentos para aplicações futuras, num curto prazo ela é mais dependente de conhecimentos que sejam mais facilmente traduzidos numa forma prática e comercial exigida pelo cotidiano (Twiss, 1986). Entretanto, a contribuição de $P \& D$ não está restrita à inovação tecnológica; a implementação de $\mathrm{P} \& \mathrm{D}$ pela firma é sensivelmente relevante para ampliar a capacidade de aprendizagem da mesma e, por conseguinte, torná-la capaz de interpretar melhor as oportunidades tecnológicas (Cohen \& Levinthal, 1989). A existência de rotinas, as quais, se somadas a outros aspectos, tais como a adaptação e a modificação baseados na experiência e no fluxo de informações futuras, levam ao aprendizado, seja observando o ambiente interno, seja observando o ambiente externo da empresa (Nelson \& Winter, 1982). Esse processo de aprendizagem originário do dia-a-dia da empresa, possivelmente baseado em elementos informais, pode ocorrer de várias formas, seja pela realização do trabalho, pelo uso de determinados instrumentos ou equipamentos, pelo próprio erro, pelo estudo e, também, pela movimentação dos competidores (Pavitt, 1992). Tais elementos somam-se a outras competências da empresa e podem contribuir para que a mesma crie um diferencial frente aos concorrentes de modo a sustentar suas atividades no mercado. Isso, entretanto, pode ser sensivelmente mais difícil se a empresa não for capaz de desenvolver por si só boa parte da tecnologia que vai agregar valor aos seus negócios.

Porém, não basta apenas gerar tecnologia. Lander et al (1995) observaram que as melhores empresas são justamente aquelas que, além de saber alinhar P\&D com a estratégia 
corporativa, também sabem como mensurar esse alinhamento. Mais especificamente, os autores sugerem quatro elementos que seriam imprescindíveis para uma melhor tomada de decisão no que diz respeito aos projetos de $\mathrm{P} \& \mathrm{D}$, ou seja, uma decisão mais efíciente ocorreria quando a empresa (i) mede a contribuição de $\mathrm{P} \& \mathrm{D}$ aos seus objetivos estratégicos; (ii) usa ferramentas e técnicas para tomadas de decisão; (iii) coordena negócios de longo prazo e planejamento de P\&D; e (iv) estabelece acordos baseados em metas claras e mensuráveis. $\mathrm{O}$ objetivo do presente trabalho, contudo, não se estende à análise destes aspectos. $\mathrm{O}$ foco da nossa atenção está na forma como a tecnologia é acessada, uma vez que este é pressuposto para o estabelecimento de uma posição competitiva na indústria de polímeros. Examinaremos, a seguir, o modo inicial de acesso a tecnologia para a implantação da indústria nacional.

\section{A indústria de polímeros e a tecnologia no Brasil}

O Brasil pode ser citado como um dos países em desenvolvimento que mais se valeu da importação de tecnologia para a implantação de seu parque industrial, particularmente no que diz respeito à indústria petroquímica, onde se insere a indústria de polímeros. $\mathrm{O}$ estabelecimento da indústria petroquímica brasileira ocorreu de maneira mais intensa na década de 70, com a criação quase simultânea de três pólos petroquímicos localizados em São Paulo, Camaçari (Bahia) e Triunfo (Rio Grande do Sul). Essencialmente, as firmas foram criadas adotando-se um modelo conhecido como tripartite, o qual envolvia a formação de joint-ventures com empresas estrangeiras. Essas empresas estrangeiras se responsabilizaram pelo fornecimento das tecnologias necessárias à implantação da referida indústria, uma vez que o país não contava, na época, com uma infra-estrutura tecnológica capaz de impulsionar tamanho investimento.

Em plano mundial, o que se observava na época da implantação da indústria petroquímica no país era que os contratos de transferência de tecnologia eram assinados entre as firmas, sem que houvesse qualquer intervenção governamental. As partes eram livres para estabelecer as bases dos acordos. Entretanto, essa total liberdade de ação gerou um número abusivo de cláusulas contratuais, dando poderes quase ilimitados aos fornecedores de tecnologia e, consequentemente, vedando quase que por inteiro o acesso ao desenvolvimento tecnológico por parte dos adquirentes (McCulloch, 1981). A partir da década de 70, diversos países, conscientes desses problemas, passaram a adotar regulamentações legais mais severas para controlar o processo de importação de tecnologia. Seguindo essa tendência, em 1971, entrava em vigor no Brasil o Código da Propriedade Industrial, que regulamentava de forma bastante restrita, todas as formas de transferência de tecnologia. Através dessa legislação, o Instituto Nacional de Propriedade Industrial (INPI) tinha o poder de intervir nos contratos, proibir cláusulas contratuais e mesmo impedir a realização do negócio, caso houvesse tecnologia similar sendo desenvolvida no país (Cunha Lima, 2002).

As empresas criadas a partir do modelo tripartite se desen- volveram dentro de um ambiente onde o aparelho governamental exercia forte intervenção no mercado. Além disso, as respectivas unidades fabris daquelas empresas se caraterizavam por possuírem, em geral, capacidades instaladas com a finalidade primordial de atendimento do mercado interno. Até há bem pouco tempo, a grande totalidade das empresas de polímeros no Brasil eram monoprodutoras e não tinham economia de escopo. Fatores estes que tornavam difícil o processo de integração à nova realidade de um mundo, que ao longo das duas últimas décadas, tem presenciado a intensificação do fenômeno da globalização, capaz de promover um aumento na inter-relação econômica dos países. Essa nova ordem econômica atingiu o Brasil principalmente a partir de 1990, com a adoção da política governamental de promover o distanciamento entre o Estado e o mercado. Nesse sentido, as ações mais marcantes do governo foram a abertura do mercado brasileiro, através da diminuição das alíquotas de importação, e a privatização de muitas empresas nas quais ele participava como sócio majoritário, incluindo-se aí aquelas pertencentes à indústria de polímeros. Somando-se a isso, o governo brasileiro promulgou a nova lei de patentes em 1996, visando adequar o país aos novos cenários de globalização e comércio internacional e visando pacificar os clamores internacionais contra a excesso de proteção existente no mercado brasileiro, no que se refere à transferência de tecnologia para firmas locais.

Esses fatos, aos poucos, transformou o perfil da indústria brasileira de polímeros, principalmente através das últimas fusões e aquisições ocorridas em 2001. Hoje já se delineia um novo perfil da petroquímica brasileira, diferente daquele da década passada, quando se deu o processo de privatização da indústria. A extinção de um mercado protegido por elevadas alíquotas de importação, das subvenções e das facilidades para exportar os excedentes de produção, aliada a uma forte concorrência de empresas estrangeiras, fez com que a indústria brasileira de polímeros mudasse seu perfil. Presume-se, portanto, que a mesma tenha adotado ações para assegurar sua sobrevivência, dentre as quais uma busca pela autonomia tecnológica capaz de fortalecer seu posicionamento competitivo. Tal aspecto foi examinado pela presente pesquisa conforme a metodologia adotada a seguir.

\section{Metodologia}

A partir do objeto de análise da presente pesquisa e o conhecimento da forma como as empresas brasileiras produtoras de polímeros tiveram acesso a tecnologia, a metodologia utilizada envolveu inicialmente a montagem de uma base de dados sobre todos os contratos de transferência de tecnologia, averbados no Brasil para a área de polímeros, no período de 1985 a 2001. Subseqüentemente, foi realizada uma série de entrevistas com profissionais responsáveis pela área tecnológica de sete empresas produtoras de polímeros. Esta parte qualitativa visava um entendimento mais aprofundado do objeto de pesquisa tendo em vista que a base de dados limita a nossa análise a apenas uma forma de acesso 
a tecnologia (aquisição de terceiros) e pouco poderíamos saber sobre a geração endógena da mesma.

As entrevistas, de caráter semi-estruturado, foram guiadas em boa parte pela literatura especializada (e.g. Kvale, 1996; Yin, 1994). Por sua vez, a montagem da base de dados sobre contratos de transferência de tecnologia baseou-se nas informações gentilmente concedidas pelo Instituto Nacional da Propriedade Industrial (INPI) e o período utilizado foi decorrente da disponibilidade das informações por aquele instituto. Tomou-se como o universo da amostragem todos os contratos averbados e classificados na Seção C, Classe C08 da Classificação Internacional de Patentes, que se refere ao setor industrial de produção de polímeros. Essa classe se divide em subclasses que incluem toda a tecnologia de preparação de macromoléculas, sua modificação química, catalisadores, aditivos, processamento químico do polímero e suas composições poliméricas.

Cabe lembrar que, embora a nova lei de patentes de 1996 tirasse do INPI qualquer direito de intervenção em cláusulas contratuais de transferência de tecnologia, ela manteve a obrigatoriedade de averbação de todos os contratos naquele instituto. Essas averbações são feitas de acordo com as seguintes categorias: (1) exploração de patentes (EP); (2) uso da marca (UM); (3) fornecimento de tecnologia (FT); (4) serviços de assistência técnica e científica (SAT); (5) franquia (FRA); e (6) outros (OUT).

A exploração de patentes e o uso da marca se referem a contratações relacionadas aos direitos de propriedade industrial pleiteados no Brasil. O fornecimento de tecnologia é uma categoria reservada a contratações envolvendo a comercialização de tecnologia não protegida por patentes trata-se de contratos de know-how. O contrato de serviços de assistência técnica e científica estipula as condições de obtenção de técnicas, métodos de planejamento e programação, bem como pesquisas, estudos e projetos destinados à execução ou prestação de serviços especializados. Os contratos de franquia envolvem prestação de serviços, transferência de tecnologia, transmissão de padrões operacionais e outros aspectos, além do uso de marcas e patente. E "outros" incluem divisão de custos de pesquisa, quando realizada envolvendo diversas firmas. Tais modalidades de contratos hoje regulam o fluxo tecnológico entre empresas estabelecidas no país e os fornecedores, geralmente localizados no exterior, havendo ou não vínculo entre esses fornecedores e os consumidores. Isto significa que o fluxo de tecnologia que ocorre entre matrizes e subsidiárias, como o que ocorre entre empresas sem qualquer vínculo, são enquadrados naquelas modalidades de contrato.

\section{Contratos de transferência de tecnologia no Brasil}

A fim de verificar como a indústria brasileira de polímeros lida com sua tecnologia, foi construída uma base de dados, contendo todos os contratos de transferência de tecnologia averbados no INPI, classificados na Seção C, Classe C08, no período entre 1985 a 2001. As tabelas, a seguir, apresentam os resultados obtidos a partir dessa base de dados. Observa- se que, nesse período, foram registrados 208 contratos segundo as diferentes categorias contratuais, conforme a classificação do INPI:

- Fornecimento de Tecnologia (FT)

- Exploração de Patentes (EP)

- Serviços de Assistência Técnica (SAT)

- Outros (OUT)

$\mathrm{Na}$ categoria "Outros" inclui-se, por exemplo, rateio de pesquisa, que deve ser entendido como os contratos de participação nos custos de pesquisa e desenvolvimento tecnológico. Esses contratos estabelecem as regras para o fluxo de tecnologia entre empresas domiciliadas no país e centros de pesquisa ou empresas com capacidade de geração de tecnologia no país ou no exterior, ou entre empresas com vinculação societária entre si. Como era de se esperar, não houve caso de contratos de uso de marcas ou de franquias averbados no setor de polímeros.

Observa-se na tabela 1 que, no período de dezessete anos, foram averbados um total de 208 contratos de transferência de tecnologia no INPI, pela indústria brasileira de polímeros. Desses, 112 contratos, mais de $50 \%$, foram de fornecimento de tecnologia (FT), ou seja, transações que envolvem tecnologia não patenteada e, portanto, tecnologia não sujeita às leis de patentes. Foram 72 (34,62\%) o número de averbações de contratos de Serviços de Assistência Técnica (SAT). Cabe aqui lembrar que o SAT estipula as condições de obtenção de técnicas, métodos de planejamento e programação, bem como pesquisas, estudos e projetos destinados à execução ou prestação de serviços especializados. O número de averbações de contratos de exploração de patentes foi somente 20.

A análise da tabela 1 mostra a tendência do Brasil para a "compra" de tecnologia e de assistência técnica para serviços especializados. Pode-se observar que, aproximadamente, $88,5 \%$ (FT+SAT) das averbações de contratos no INPI tratam dessas categorias. Entretanto, os contratos para a exploração de patentes, que estão sujeitos às leis de propriedade industrial, são pouco utilizados pela indústria brasileira de polímeros, representando cerca de $10 \%$ do total.

Os dados agregados acima não nos permitem precisar quaisquer modificações na tendência dos contratos. Podemos dizer apenas em linhas gerais que, em média, 12 contratos por ano foram firmados ao longo do período estudado, sendo em média 7 contratos de FT, 4 de SAT e somente 1 de

Tabela 1. Contratos averbados no INPI - setor de polímeros (1985-2001)

\begin{tabular}{lcc}
\hline \multicolumn{1}{c}{ Categoria } & Número & \% \\
\hline Fornecimento de Tecnologia (FT) & 112 & 53,85 \\
Serviço de Assistência Técnica (SAT) & 72 & 34,62 \\
Exploração de Patente (EP) & 20 & 9,62 \\
Outros (OUT) & 4 & 1,91 \\
Total & $\mathbf{2 0 8}$ & $\mathbf{1 0 0 , 0 0}$ \\
\hline
\end{tabular}


EP. Levando-se em consideração que o número de empresas nacionais produtoras de polímeros era cerca de 15 no período estudado, um total de 7 contratos anuais de fornecimento de tecnologia pode acenar para uma provável dependência de fornecedores externos. Isso pode não ser necessariamente verdadeiro pois não temos nenhuma referência para efeitos comparativos. Todavia, os dados obtidos junto ao INPI deixaram claro a participação de empresas estrangeiras como fornecedoras de tecnologia. Dos 208 contratos averbados, aproximadamente $90 \%$ dos fornecedores eram estrangeiros. Além disso, 2/3 dos contratos em que o fornecedor era uma empresa nacional foram assinados na segunda metade da década de 80 , ou seja, a presença do fornecedor nacional parece ter ficado ainda mais remota recentemente. Ao desagregarmos os dados ano a ano, chegamos ao gráfico da Figura 1 que talvez possa nos dar maiores informações.

Examinando-se mais detalhadamente os dados, observamos que na segunda metade da década de 80 a indústria brasileira de polímeros registrou uma média de 10 contratos anuais de fornecimento de tecnologia (FT). Já no restante do período, essa média foi reduzida à metade. Em contrapartida, o número de contratos de assistência técnica (SAT) que na segunda metade da década de 80 apresentava uma média de 3 contratos por ano, teve um acréscimo de um pouco mais de $50 \%$ no restante do período estudado. Tal comportamento poderia ser esperado uma vez que a tecnologia, após adquirida, necessita de manutenção regular para que a planta continue em operação. Contudo, a queda do número de contratos de fornecimento de tecnologia também pode ser explicada pela mudança no cenário econômico nacional, cujo Programa Nacional de Desestatização previa também uma reforma no sistema tarifário. Isto é, a grande diminuição das alíquotas de importação pode ter motivado empresas estrangeiras a comercializarem seus produtos diretamente no país, ao invés de licenciarem suas tecnologias para produtores locais. Em 1993 a tarifa para importação chegou ao seu mínimo e a concorrência de produtos importados pode ter se intensificado de modo que as empresas brasileiras necessitaram se atualizar tecnologicamente, ou mesmo ampliar suas capacidades produtivas com o objetivo de ganhos de economia de escala para reduzir o preço de seus produtos. Isso pode ser uma das razões para o acréscimo no número de

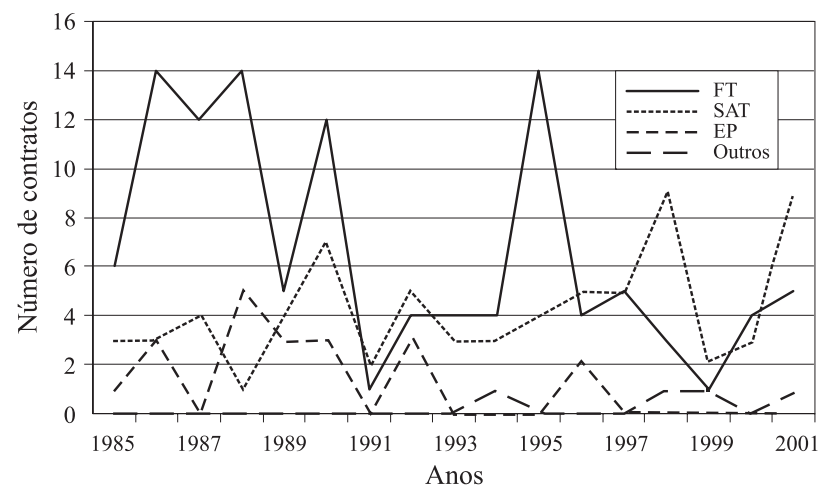

Figura 1. Contratos anuais em polímeros firmados no INPI (1985-2001)
Tabela 2. Contratos averbados no INPI - setor de polímeros, de acordo com o tipo de contratante (1985-2001)

\begin{tabular}{lccc}
\hline \multirow{2}{*}{ Categoria } & \multicolumn{2}{c}{ Número de contratos } & \\
\cline { 2 - 3 } & $\begin{array}{c}\text { Mesmo } \\
\text { grupo }\end{array}$ & Terceiros & \\
\hline Fornecimento de Tecnologia (FT) & 18 & 94 & 112 \\
$\begin{array}{l}\text { Serviço de Assistência Técnica } \\
\text { (SAT) }\end{array}$ & 8 & 64 & 72 \\
$\begin{array}{l}\text { Exploração de Patente (EP) } \\
\text { Outros (OUT) }\end{array}$ & 8 & 12 & 20 \\
Total & 34 & 4 & 4 \\
\hline
\end{tabular}

contratos de fornecimento de tecnologia em 1995. O argumento pode parecer contraditório com base no exposto anteriormente que empresas estrangeiras detentoras da tecnologia não teriam motivação para licenciar já que poderiam importar. Contudo, cabe lembrar que nem sempre o detentor da tecnologia comercializa o produto que será gerado por tal tecnologia; muitos têm na própria tecnologia para manufatura o seu produto, isto é, não se detêm ao produto manufaturado mas à tecnologia capaz de produzi-lo.

Para examinar se os contratantes de tecnologia tinham vínculo formal entre si, os contratos foram divididos em dois grupos: o primeiro englobando contratos firmados entre empresas do mesmo grupo, envolvendo a transferência interna de tecnologia e o segundo englobando contratos firmados com terceiros, isto é, envolvendo transferência de tecnologia entre empresas não-relacionadas. A tabela 2 apresenta os resultados.

Observa-se que 174 contratos foram firmados entre terceiros, em geral, um fornecedor estrangeiro e um comprador brasileiro. Por outro lado, os 34 casos de transferência dentro do mesmo grupo estão associados a negociações entre matrizes e subsidiárias. Do total de 112 contratos relativos a comercialização de tecnologia que não é patenteada (FT), 94 foram firmados entre terceiros. Serviços técnicos também foram firmados, em sua quase totalidade, entre terceiros. Examinando-se individualmente os casos de transferência de tecnologia, foi observado que, quando o fornecimento de tecnologia ocorria entre terceiros, ele sempre era combinado com serviços técnicos. Entretanto, esta peculiaridade não foi observada quando a transferência se dava dentro do mesmo grupo; nesses casos, FT e SAT eram assinados independentemente.

O número de contratos de exploração de patentes é bastante pequeno, em comparação com os demais instrumentos legais. Entretanto, deve ser ressaltado que quando eles foram firmados entre terceiros, geralmente eles eram combinados com FT ou com SAT. Pelo contrário, quando eles foram firmados no mesmo grupo, não foi observado nenhum outro contrato relacionado. Isto significa que, quando são negociados contratos de exploração de patentes por empresas brasileiras, elas, geralmente, também negociam o suprimento de know-how e/ou serviço de assistência técnica para que a patente possa ser implementada. Isso talvez ratifique a incapacidade 
das empresas nacionais em utilizarem suas próprias competências técnicas para copiarem tecnologia de terceiros. Isso pode não ser verdadeiro pois adquirindo todo o pacote a implementação pode ser mais rápida; mas por outro lado pode criar maiores restrições a absorção da tecnologia.

Os dados sugerem que ainda há dependência das empresas brasileiras perante a tecnologia estrangeira. Todavia, isso pode não ser necessariamente verdadeiro uma vez que as referidas tabelas retratam apenas um fluxo unidirecional e não deixam claro até que ponto tais contratos são em decorrência de licenciamento recíproco de tecnologia. Além disso, até onde os pesquisadores estavam cientes, não haviam dados disponíveis de outros países que pudessem elucidar mais se essa é uma prática comum no setor ou se os dados retratam de fato dependência tecnológica.

As informações obtidas sobre as transações envolvendo tecnologia no Brasil são, a seguir, cotejadas com entrevistas com os principais responsáveis pelas atividades tecnológicas nas empresas brasileiras produtoras de polímeros.

\section{Atividades tecnológicas e as empresas de polímeros}

De acordo com os entrevistados, o processo de abertura de mercado instituído na década de 90 expôs a indústria nacional à uma severa concorrência. A redução de ambas as barreiras alfandegárias e não-alfandegárias facilitou muito a entrada de produtos importados e isso demandou da indústria nacional uma completa restruturação para poder se sustentar. No passado, a predominância de um mercado eminentemente fechado assegurava aos produtores de polímeros a certeza de que seus nichos não seriam ameaçados e, portanto, não havia motivos para uma provável mobilização no sentido de desenvolver competências organizacionais, visando uma disputa com eventuais concorrentes. E, de acordo com um dos informantes, na época em que o mercado era protegido e os preços eram estabelecidos pelo governo, a ineficiência das empresas acabava embutida nos preços. Isso se modificou drasticamente e as empresas precisaram centralizar as atividades tecnológicas no curto prazo.

A maior parte dos entrevistados assegurou que as atividades de $\mathrm{P} \& \mathrm{D}$ se fazem necessárias para que tenham acesso à tecnologia e, portanto se sustentem no mercado. No entanto, as modificações ocorridas na última década fizeram com que o enfoque das atividades tecnológicas fosse direcionado à melhoria de qualidade dos produtos, ao aumento da eficiência das plantas produtivas e a um melhor atendimento aos clientes. O planejamento estratégico de longo prazo para o desenvolvimento tecnológico endógeno, que talvez já fosse restrito, parece ter sido reduzido substancialmente. Tal fato foi exemplificado por um dos informantes, o qual afirmou que a empresa só vai decidir o que fazer com a tecnologia usada na fabricação de seus produtos quando terminar o prazo de vigência do contrato. Isso talvez retrate a ainda dependência tecnológica das empresas nacionais frente às estrangeiras, como anteriormente apontado pela análise dos dados referentes aos contratos de transferência de tecnologia.

Somando-se a isso, foi observado, também, que as empresas da amostra entendem que a tecnologia mais avançada tende a ficar cada vez mais concentrada em umas poucas empresas, as quais irão agregar mais as vantagens competitivas. Apesar disso, algumas empresas acreditam que haverá permanente oferta de licenciamento, mesmo que em alguns momentos sejam apresentadas restrições; principalmente quando os licenciadores forem seus concorrentes diretos. Tais restrições de empresas detentoras de tecnologia parecem já ter ocorrido de fato, o que vem obrigando algumas empresas a buscar por si só o desenvolvimento endógeno de tecnologia. Algumas das empresas entrevistadas asseguraram que vêm tendo êxito com esse comprometimento tecnológico, mas ainda é cedo para prever até que ponto elas serão realmente bem sucedidas.

Dentre as empresas estudadas, todas asseguraram o exercício de atividades de $\mathrm{P} \& \mathrm{D}$ in house. Entretanto, o foco na melhoria de produtos e processos pode significar que pouco pode ser esperado de investimentos em pesquisa básica; o que, de fato, foi constatado pelas entrevistas. Apesar de confirmarem a existência da função $P \& D$, apenas uma das empresas estudadas relatou estar realizando pesquisa básica em sua unidade operacional. Todavia, a intensidade de pesquisa básica endógena foi caracterizada pelo informante como muito pequena. De acordo com as empresas entrevistadas, as atividades de pesquisa básica, quando implementadas, são desenvolvidas em parcerias com universidades em campos de acentuada importância, nos quais as empresas precisam ter competência tecnológica para o andamento futuro de seus negócios. A não realização de pesquisa básica endógena por grande parte das empresas entrevistadas teve como justificativa as dificuldades econômicas pelas quais as empresas brasileiras, de um modo geral, estão passando. Isso fez as empresas buscarem resultados mais imediatos, deixando de lado atividades cujos resultados são obtidos em um prazo mais longo. Muitas vezes, as próprias empresas nem dispõem dos recursos humanos para a realização de pesquisa básica, cuja contratação, em geral, ultrapassa seus limites orçamentários. Contudo, apesar da contenção de despesas, algumas empresas se mostraram conscientes de que precisam retomar o mais breve possível suas atividades de longo prazo pois foram justamente os investimentos de longo prazo que serviram de base para os seus negócios atuais.

A solução para $P \& D$ de longo prazo poderia advir de parcerias com universidades ou centros de pesquisa, como, de fato, foi relatado pelos entrevistados. Entretanto, de acordo com as entrevistas, ainda existem algumas barreiras para tal cooperação. Por exemplo, nem sempre a própria universidade tem o corpo técnico necessário à realização da pesquisa básica de interesse. Outra dificuldade apontada foi a dificuldade por parte das universidades para cumprirem os prazos. Ainda, os projetos estimulados pelo governo sofrem da falta de continuidade devido à alta rotatividade de mão-deobra e ao cancelamento de verbas no decorrer do projeto.

No que se refere aos outros dois tipos da denominada pesquisa industrial, isto é, pesquisa aplicada e desenvolvimento experimental, foi relatado pelos informantes que os esforços 
tecnológicos têm-se voltado não mais para adaptação dos produtos à demanda local e dos processos às condições locais. $\mathrm{O}$ que se observa é o interesse das empresas nacionais em tornar seus portfolios de produtos competitivos a nível internacional. Isso, de acordo com entrevistados, levou as empresas a ter uma maior preocupação com as especificações de seus produtos para que os mesmos pudessem atender aos padrões internacionais de qualidade total. Para tanto, muito enfoque vem sendo dado ao aumento de eficiência das plantas e ao aperfeiçoamento dos processos de fabricação dos produtos. Somando-se a isso, tem-se buscado um melhor atendimento aos clientes e uma melhor logística para distribuição de produtos - elementos capazes de aumentar a competitividade das empresas locais.

De acordo com os entrevistados, os horizontes de tempo para as atividades de P\&D são estabelecidos em grande parte pela área comercial, que além de conhecer os clientes, estuda as tendências do mercado e mapeia a introdução de produtos concorrentes. De acordo com os entrevistados, o sincronismo dessa área com P\&D tem sido crucial para responder à demanda. As empresas estudadas se declararam incapazes, no momento, de promover altos investimentos absolutos em P\&D pois seus grupos controladores não possuem porte empresarial que justifique isso. Porém, como muito recentemente começaram a ocorrer fusões entre as próprias empresas nacionais, aquele fato já pode estar em vias de se modificar. Tal movimento vai ao encontro do que tem ocorrido mundialmente, onde os altos investimentos necessários ao desenvolvimento tecnológico têm induzido empresas multinacionais a se unirem para o desenvolvimento de atividades tecnológicas. Como esperado, diante de suas limitações tecnológicas, nenhuma das empresas estudadas cogitou a possibilidade de estarem utilizando ou de virem a utilizar a tecnologia produzida endogenamente como um ativo em negociações para terem acesso à outras tecnologias. Cabe, portanto, a pergunta se isso é falta de visão de longo prazo ou se as perspectivas para as empresas nacionais não são otimistas?

Das empresas pertencentes à amostra, todas ratificaram a idéia de que capacitar-se tecnologicamente, a ponto de ocuparem alguma liderança tecnológica mundial, é extremamente difícil. Algumas empresas acreditavam que seria mais apropriado estabelecerem parcerias com empresas líderes para agregar aos seus portfolios, os produtos das mesmas. Além do que, essa complementação de linha também poderia proporcionar um melhor atendimento aos clientes, pois eles normalmente usam mais de um tipo de produto e preferem receber de um único fornecedor. Contudo, parece que as empresas nacionais têm se deparado com propostas inaceitáveis para esse tipo de parceria, uma vez que algumas detentoras de tecnologia somente se dispuseram a firmar um acordo em bases extremamente vantajosas para si. Isso, portanto, parece ratificar o posicionamento das empresas líderes no setor, de restrição ao licenciamento de suas tecnologias, o que poderá, fatalmente, induzir a uma completa restruturação no setor ou ao desalojamento das empresas nacionais por suas concorrentes multinacionais.

\section{Análise dos resultados}

Os dados sobre contratos de transferência de tecnologia sugerem que o acesso à tecnologia pelas empresas de capital nacional, em sua maioria, se dá através de contratos de fornecimento de tecnologia. Por definição, os contratos de fornecimento de tecnologia nada mais são do que contratos de know-how. Nesses tipos de contrato, o cedente (fornecedor) da tecnologia garante o repasse do conhecimento do "como fazer" ao cessionário, através de cláusulas contratuais. Essa é, sem dúvida alguma, a forma mais rápida de acesso às tecnologias mais avançadas. Contudo, as entrevistas permitiram elucidar que esse rápido acesso não significa que a tecnologia é absorvida. As empresas estudadas relataram que, em sua maioria, o fornecedor de tecnologia é um sócio e impõe restrições a futuros desenvolvimentos tecnológicos com base na tecnologia cedida. Cabe lembrar que, geralmente, os contratos de fornecimento de tecnologia são assinados simultaneamente com os de assistência técnica, o que pode tornar ainda se mais difícil para as empresas nacionais terem seus próprios projetos de pesquisa.

O baixo percentual de contratos de exploração de patentes, que se referem a contratações relacionadas aos direitos de propriedade industrial, pode ser explicado pelo fato de não incluírem o repasse do know-how. A Lei de Propriedade Industrial não determina a obrigatoriedade da descrição do know-how no relatório descritivo do pedido de patente e, portanto, o licenciado não tem acesso a ele na tecnologia licenciada. Isso implicaria em despesas com P\&D para seu desenvolvimento. Os dados indicam que a indústria brasileira de polímeros prefere a compra do "pacote tecnológico". Isto poderia ser explicado pela limitada competência técnica das empresas nacionais. Para se operacionalizar um documento de patente é necessário um conhecimento específico e bastante experiência profissional, o que, muitas vezes, não está disponível nas empresas.

As empresas brasileiras afirmaram já terem realizado trabalhos para promover a otimização e o desgargalamento de seus processos, além de consolidarem serviços de assistência técnica e de desenvolvimento de novos grades de produtos. No entanto, apesar de buscarem ter acesso às tecnologias necessárias para suas operações por meio de geração endógena, as empresas brasileiras de polímeros ainda se valem, em grande parte, de fontes externas como provedoras de insumos tecnológicos. A provável dependência tecnológica observada no presente estudo poderia ser explicada, entre outros fatores, pelo processo cíclico de expansão e retração do setor, associado às oscilações da atividade econômica e à própria dinâmica de investimento do setor; o elevado grau de incerteza e risco inerentes às atividades tecnológicas inovadoras. Além disso, o estágio tecnológico de relativa maturidade em que se encontra a indústria de polímeros contribui para que o progresso técnico ocorra através de inovações incrementais e isso pode incorrer em custos muito altos para um projeto de prazo maior. Esse fato pode influenciar o comportamento das empresas em relação aos investimentos em 
atividades de inovação tecnológica. Somando-se a isso, o porte relativamente pequeno das empresas brasileiras, em relação aos seus competidores internacionais, parece que tem sido decisivo para a escolha da tecnologia externa em detrimento à geração in house. Contudo, a expectativa positiva da relação entre investimentos em atividades de $\mathrm{P} \& \mathrm{D}$ e rentabilidade parece ainda não ter sido capaz de mobilizar as empresas nacionais de polímeros a um maior esforço nesse sentido. Esse esforço pode contribuir para o aprendizado da firma e, assim, influenciar a forma como a empresa manipula as variáveis que, em conjunto, solidificam o processo de inovação. Esse comportamento, portanto, pode tornar difícil não apenas o acesso à tecnologia essencial para a sustentação dos negócios no longo prazo, mas também a efetiva absorção da tecnologia e geração de habilidades e competências.

\section{Conclusões}

A integração de $\mathrm{P} \& \mathrm{D}$ à estratégia da empresa e a constante criação de nova tecnologia são dois elementos essenciais para a sobrevivência da empresa a longo prazo em um ambiente altamente competitivo, como é o encontrado no cenário atual de um mundo globalizado economicamente.

As entrevistas realizadas mostraram que as empresas brasileiras de polímeros concentram suas atividades de $\mathrm{P} \& \mathrm{D}$ em curto prazo, uma vez que alegam não ter porte nem recursos disponíveis para desenvolvimentos de longo prazo, cercados da incerteza inerente ao processo.

A principal conclusão do presente trabalho é que a indústria brasileira de polímeros é fortemente dependente de importação de tecnologia para manter sua competitividade no mercado. As empresas firmam contratos de fornecimento de tecnologia em lugar de manter programas de $\mathrm{P} \& \mathrm{D}$ direcionados para essa finalidade. Por outro lado, essas empresas têm vínculos estreitos com o fornecedor de tecnologia através de contratos de assistência técnica e, muitas vezes, esse fornecedor faz parte do capital social da empresa. Isso mostra a dificuldade que têm essas firmas de manter seus próprios projetos de desenvolvimento tecnológico, sem colidir com os interesses de seus sócios estrangeiros.

Empresas multinacionais licenciam sua tecnologia quando o produto já não constitui objeto prioritário para a competitividade dessas empresas. Também existem outros casos de licenciamento voluntário por parte das empresas, quando existe o interesse de uso recíproco de tecnologia, quando está disponível um estoque de conhecimento adquirido através de $\mathrm{P} \& \mathrm{D}$, sem que haja interesse da empresa geradora em exploração, ou quando a tecnologia é do tipo commodity, isto é, produto não-estratégico e disponível a partir de diversas fontes (Hemais, 1997) Pode-se prever que as empresas nacionais não terão muitas oportunidades de conseguir o licenciamento de tecnologia representando o estado-da-arte. Ainda mais quando se sabe que não existe tecnologia própria que possa servir de objeto de barganha em um caso de exploração recíproca de conhecimentos. Resta, pois, às empresas nacionais investir em nichos restritos, onde não precisem com- petir com empresas tecnologicamente mais avançadas, e onde elas podem se tornar únicas, como, por exemplo, desenvolver serviços de atendimento exclusivo aos clientes.

O panorama apontado limita as ações das empresas nacionais e dificilmente contribuirá para torná-las tecnologicamente ativas, possibilitando apenas estratégias defensivas em relação ao mercado, ou seja, ações centradas no curto prazo através de respostas mais imediatas às exigências do cotidiano. De acordo com Twiss (1986), esse comprometimento com o dia-a-dia é essencial, mas o autor complementa ressaltando a importância de se buscar um equilíbrio entre as ações de curto, médio e longo prazo. Esse equilíbrio, porém, se torna mais difícil quando a empresa necessita dar muito mais ênfase a um determinado período de tempo.

\section{Agradecimentos}

Os autores agradecem ao $\mathrm{CNPq}$ pelo suporte à presente pesquisa.

\section{Referências Bibliográficas}

1. Bean, A. S. - Why some R\&D organizations are more productive than others. Research Technology Management, jan./feb., p.25-29 (1995).

2. Bodewitz, H.; De Vries, G. \& Weeder, P. - Towards for technology-oriented R\&D Processes. Research Policy, v.17, p.213-224 (1988).

3. Chesbrough, H. \& Teece, D. J. - Organizing for innovation. Harvard Business Review, jan./feb, p.65-73 (1996).

4. Cohen, W. M. \& Levinthal, D. A. - Innovation and learning: The two faces of R\&D. The Economic Journal, n.99, sep., p.569-596 (1989).

5. Cunha Lima, L. C. - Comunicação pessoal. Relastomer, Rio de Janeiro (2002).

6. Deschamps, J. P. \& Nayak, R. - Como se destacar na prateleira. Revista Exame, n.4, fev., p.62-64 (1997).

7. Hasenclever, L. (1997). Dinâmica e gestão da inovação: o papel das empresas industriais químicas. Tese de Doutorado. COPPE/ Universidade Federal do Rio de Janeiro.

8. Hemais, C. A. - Model of international transfer of technology: a theoretical approach. Technology Management: Strategies \& Applications, v.3, p.213227 (1997).

9. Henry, N.; Massey, D. \& Wield, D. Along the road: R\&D, society and space. Research Policy, v.24, n.5, p.707726 (1995).

10. Kvale, S. - InterViews - an introduction to qualitative research interviewing. Thousand Oaks, CA: Sage, (1996). 
11. Lander, L.; Matheson, D.; Menke, M. M. \& Ransley, L. Improving the $\mathrm{R} \& \mathrm{D}$ decision process. Research Technology Management, jan./feb., p.40-43 (1995).

12. Marcovitch, J. - Ciência e tecnologia: fatores de desenvolvimento sócio-econômico. In: Maximiano, A.C.A., Johnson, B. B.; Vasconcellos, E. \& O'Keefe, W. M. (Ed.). Administração do processo de inovação tecnológica. São Paulo: Editora Atlas, cap. 2, p.25-49 (1980).

13. McCulloch, R. - Technology transfer to developing countries: implications of international regulation, Annals American Academy of Political Science, 458, November, 110-122 (1981).

14. Nelson, R. \& Winter, S. - An evolutionary theory of economic change. Cambridge: The Belknap Press of Harvard University Press, (1982).

15. Pavitt, K. - Sectoral patterns of technical change: towards a taxonomy and a theory. Research Policy, v.13, p.343373 .(1984).

16. Pavitt, K. - Some foundations for a theory of the large innovating firm. In: Dosi, G.; Giannetti, R. e Toninelli, P. A. (Ed.). Technology and enterprise in a historical perspective. Oxford: Clarendon Press, chap. 7, p.212228 (1992).
17. Pereira, H. M. S.; Sbragia, R. \& Carvalho, A. C. R. Experiência de avaliação de resultados de P\&D. Revista de Administração, v.25, n.1, jan./mar., p.70-83 (1990).

18. Pettigrew, A. - The awakening giant: continuity and change in Imperial Chemical Industries. Oxford: Blackwell, (1985).

19. Roussel, P. A.; Saad, K. N. \& Bohlin, N. - Pesquisa \& Desenvolvimento: como integrar P\&D ao plano estratégico e operacional das empresas como fator de produtividade e competitividade. São Paulo: Makron Books do Brasil, (1992).

20. Schumann, P. A.; Ransley, D. L. \& Prestwood, D. C. L. Measuring R\&D performance. Research Technology Management, may/jun., p.45-54, (1995).

21. Thayer, A. M. - Justifying technology's value challenges industry R\&D managers. C\&EN News, n.6, feb., p.1014, (1995).

22. Twiss, B. - Managing technological innovation. 3.ed. London: Pitman, (1986).

23. Yin, R. - Case study research - design and methods. Newbury Park, CA: Sage, (1994).

Enviado: 25/05/04

Aprovado: 31/08/04 